\title{
Fungos anamorfos decompositores do folhedo de Caesalpinia echinata Lam.
}

\author{
ROSELY ANA PICCOLO GRANDI ${ }^{1,2}$ e THACYANA DE VALOIS SILVA ${ }^{1}$
}

(recebido: 18 de agosto de 2005; aceito: 25 de maio de 2006)

\begin{abstract}
Anamorphic fungi on leaf litter of Caesalpinia echinata Lam.). Samples of leaf litter of Caesalpinia echinata Lam. were collected from January 2002 to April 2004, mostly in the São Paulo Municipality, to isolate decomposing anamorphic fungi. The washing technique was applied on plant material and then incubated in moist chambers. Forty-six taxa were identified, 43 belonging to Hyphomycetes and three belonging to Coelomycetes. Dictyosporium zeylanicum Petch, Gyrothrix grisea Piroz., Sporidesmium cf. filirostratum Cabello, Cazau \& Aramb., S. inflatum (Berk. \& Ravenel) M.B. Ellis, and S. triangulare Matsush. were recorded for the first time from Brazil. For these taxa descriptions, illustrations, comments and geographical distribution are presented.
\end{abstract}

Key words - Brazil-wood, Coelomycetes, diversity, Hyphomycetes

RESUMO - (Fungos anamorfos decompositores do folhedo de Caesalpinia echinata Lam.). Folhas em decomposição de Caesalpinia echinata Lam. foram coletadas, de janeiro de 2002 a abril de 2004, a maioria no Município de São Paulo, para isolamento de fungos anamorfos que decompõem esse substrato. Para análise dos fungos aplicou-se no folhedo a técnica de lavagem e incubação em câmaras-úmidas. Quarenta e seis táxons foram identificados, 43 pertencentes aos Hyphomycetes e três aos Coelomycetes. Dictyosporium zeylanicum Petch, Gyrothrix grisea Piroz., Sporidesmium cf. filirostratum Cabello, Cazau \& Aramb., S. inflatum (Berk. \& Ravenel) M.B. Ellis e S. triangulare Matsush. são registrados pela primeira vez para o Brasil. Para esses táxons são apresentados descrições, ilustrações, comentários e distribuição geográfica mundial.

Palavras-chave - Coelomycetes, diversidade, Hyphomycetes, pau-brasil

\section{Introdução}

Os fungos anamorfos fazem parte da micota decompositora presente no solo de diversos ecossistemas. O folhedo depositado é colonizado por inúmeras espécies que contribuem para a degradação de vários substratos e que, em última análise, participam da reciclagem de nutrientes e enriquecimento do solo.

O folhedo de algumas plantas já foi estudado quanto à presença de fungos anamorfos decompositores, utilizando a técnica da lavagem sucessiva de substratos. Assim, a literatura para os fungos encontrados em Alchornea triplinervia (Spreng.) Müll. Arg., Cedrela fissilis Vell., Euterpe edulis Mart., Miconia cabussu Hoehne e Tibouchina pulchra Cogn., foi mencionada em Grandi \& Gusmão (2002).

Folhas em decomposição de Caesalpinia echinata Lam. começaram a ser estudadas quanto à presença de fungos anamorfos em 2002. No decorrer do levantamento foram verificadas quatro espécies de Hyphomycetes encontradas pela primeira vez para o país e caracterizadas em Grandi \& Silva (2003). Esse trabalho é o único publicado, até o momento, que trata

\footnotetext{
1. Instituto de Botânica, Caixa Postal 4005, 01061-970 São Paulo, SP, Brasil.

2._Autor para correspondência: rapgrandi@uol.com.br
}

de levantamento de fungos decompositores do folhedo dessa planta e no qual os autores informaram todos os artigos relacionados à micota encontrada associada ao pau-brasil.

O presente trabalho dá continuidade ao conhecimento dos fungos anamorfos associados à decomposição do folhedo do pau-brasil.

\section{Material e métodos}

O folhedo de C. echinata Lam. foi coletado bimestralmente de exemplares plantados nas dependências do Instituto de Botânica e em diversos logradouros na cidade de São Paulo, de janeiro de 2002 a abril de 2004, e apenas uma vez no arboreto estabelecido na Reserva Biológica de MojiGuaçu, Município de Moji-Guaçu, SP, em junho de 2003. Os folíolos caídos ao solo e em diversos estádios de decomposição, de coloração marrom, foram coletados com pinça, colocados em sacos plásticos e levados ao laboratório para aplicação de técnica de lavagem sucessiva de substratos (Grandi \& Gusmão 1998). Em síntese, esta técnica consiste na lavagem manual vigorosa dos folíolos, por 10 vezes, com água destilada esterilizada. Após essa etapa, os folíolos foram cortados em pedaços menores (cerca de $5 \mathrm{~mm}$ de comprimento) e colocados em duas câmaras-úmidas por local de coleta. As placas foram mantidas úmidas pela adição de gotas de água destilada esterilizada, quando necessário. As câmaras-úmidas foram deixadas à temperatura ambiente; os fungos foram isolados a partir do sexto dia de incubação, prolongando-se 
as observações das placas até aproximadamente o 30 dia.

Para isolamento e identificação dos fungos utilizaram-se estiletes-agulha, retirando-os dos substratos com auxílio de estereomicroscópio e colocando-os diretamente em meio de montagem constituído de resina de álcool polivinílico adicionado de azul-de-algodão. As identificações foram feitas através da comparação morfológica e morfométrica das espécies, com a literatura específica de cada gênero encontrado. Representantes dos táxons obtidos foram selecionados e incorporados ao acervo do Herbário Científico “Maria Eneyda P. Kauffmann Fidalgo” (SP), do Instituto de Botânica. Somente foram descritos, ilustrados e comentados os táxons referidos pela primeira vez para o Brasil e para Pithomyces cf. graminicola R.Y. Roy \& J.B. Ray e Veronaea botryosa Cif. \& Montemart., cujas descrições não foram encontradas. Nomes dos autores das espécies foram abreviados segundo Kirk \& Cooper (2005).

\section{Resultados e Discussão}

Os seguintes táxons foram encontrados associados ao folhedo de $C$. echinata Lam. os quais são apresentados, dentro dos grupos Hyphomycetes e Coelomycetes, em ordem alfabética.

\section{HYPHOMYCETES}

Alternaria alternata (Fr.) Keissl., Beih. Bot. Zbl. 29:434. 1912. (1995).

Descrições e ilustrações: Ellis (1971), Grandi et al.

Material selecionado: BRASIL. SÃo PAUlo: São Paulo, Parque Estadual das Fontes do Ipiranga, Jardim Botânico de São Paulo, sobre folhas mortas de C. echinata Lam., exemplar s.n., 15-III-2002, R.A.P. Grandi \& T.V. Silva s.n. (SP307951).

Atrosetaphiale flagelliformis Matsush., Mats. Mycol. Mem. 8:14. 1995.

Descrições e ilustrações: Matsushima (1995), Castañeda-Ruiz et al. (2003).

Material selecionado: BRASIL. SÃo PAulo: São Paulo, Parque Estadual das Fontes do Ipiranga, Jardim Botânico de São Paulo, sobre folhas mortas de C. echinata Lam., exemplar número 22, 7-VIII-2002, R.A.P. Grandi \& T.V. Silva s.n. (SP307952).

Beltrania rhombica Penz., Nuovo G. Bot. Ital. 14:72. 1882.

Descrições e ilustrações: Pirozynski (1963), Gusmão \& Grandi (1996).

Material selecionado: BRASIL. SÃo PAulo: São
Paulo, Faculdade de Saúde Pública, Av. Dr. Arnaldo, sobre folhas mortas de C. echinata Lam., exemplar s.n., 12-VIII-2003, R.A.P. Grandi \& T.V. Silva s.n. (SP307953).

Beltraniella portoricensis (F. Stevens) Piroz. \& S.D. Patil, Can. J. Bot. 48:575. 1970.

Descrições e ilustrações: Ellis (1971, como Ellisiopsis gallesiae Bat. \& Nascim.), Gusmão \& Grandi (1996).

Material selecionado: BRASIL. SÃo PAUlo: São Paulo, Universidade de Santo Amaro, sobre folhas mortas de C. echinata Lam., exemplar s.n., 2-II-2004, C.G. Moreira s.n. (SP307954).

Camposporium antennatum Harkn., Bull. Calif. Acad. Sci. 1:37. 1884.

Descrições e ilustrações: Ellis (1971), Grandi et al. (1995).

Material selecionado: BRASL. SÃo PAULO: São Paulo, Parque do Ibirapuera, sobre folhas mortas de C. echinata Lam., exemplar s.n., 28-XI-2002. R.A.P. Grandi \& T.V. Silva s.n. (SP307955).

Chaetendophragmia fasciata R.F. Castañeda, Deuteromycotina de Cuba. Hyphomycetes III p.5. 1985.

Descrições e ilustrações: Castañeda-Ruiz (1985), Grandi \& Silva (2003).

Material selecionado: BRASIL. SÃo PAUlo: São Paulo, Parque Estadual das Fontes do Ipiranga, Jardim Botânico de São Paulo, sobre folhas mortas de C. echinata Lam., exemplares números 68 e 69, 30-I-2002, R.A.P. Grandi \& T.V. Silva s.n. (SP307871).

Chalara alabamensis Morgan-Jones \& E.G. Ingram, Mycotaxon 4:489. 1976.

Descrições e ilustrações: Morgan-Jones \& Ingram (1976), Grandi \& Gusmão (1996).

Material selecionado: BRASIL. SÃo PAUlo: São Paulo, viveiro da Universidade de São Paulo, próximo ao clube dos professores, sobre folhas mortas de C. echinata Lam., exemplar s.n., 20-XI-2003, R.A.P. Grandi \& T.V. Silva s.n. (SP307964).

Circinotrichum olivaceum (Speg.) Piroz., Mycol. Pap. 84:6. 1962.

Descrições e ilustrações: Pirozynski (1962), Gusmão (2003).

Material selecionado: BRASIL. SÃo PAUlo: São Paulo, Parque Estadual das Fontes do Ipiranga, Jardim Botânico de São Paulo, sobre folhas mortas de 
C. echinata Lam., exemplares números 62 e 64, 2-X-2002, R.A.P. Grandi \& T.V. Silva s.n. (SP307944).

Circinotrichum papakurae S. Hughes \& Piroz., N. Z. J. Bot. 9:40. 1971.

Descrições e ilustrações: Hughes \& Pirozynski (1971), Gusmão (2003).

Material selecionado: BRASIL. São PAULO: São Paulo, Parque Estadual das Fontes do Ipiranga, Jardim Botânico de São Paulo, sobre folhas mortas de C. echinata Lam., exemplares números 22 e 23, 7-VIII-2002, R.A.P. Grandi \& T.V. Silva s.n. (SP307947).

Cladosporium oxysporum Berk. \& M.A. Curt., J. Linn. Soc. Lond. Bot. 10:362. 1868.

Descrições e ilustrações: Ellis (1971), Grandi \& Gusmão (1996).

Material selecionado: BRASIL. SÃo PAUlo: São Paulo, Parque Estadual das Fontes do Ipiranga, Jardim Botânico de São Paulo, sobre folhas mortas de C. echinata Lam., exemplar número 102, 13-X-2003, R.A.P. Grandi \& T.V. Silva s.n. (SP307975).

Cryptophiale kakombensis Piroz., Can. J. Bot. 46:1124. 1968.

Descrições e ilustrações: Ellis (1971), Grandi \& Attili (1996).

Material selecionado: BRASIL. S̃̃o PAULO: MojiGuaçu, Fazenda Campininha, bosque do pau-brasil, sobre folhas mortas de C. echinata Lam., exemplar s.n., 7-VIII-2002, R.A.P. Grandi \& T.V. Silva s.n. (SP307965).

Curvularia lunata (Wakker) Boedijn, Bull. Jard. bot. Buitenz. III, 13:127. 1933.

Descrições e ilustrações: Batista et al. (1965), Ellis (1971).

Material selecionado: BRASIL. São PAULO: São Paulo, Parque Estadual das Fontes do Ipiranga, Jardim Botânico de São Paulo, sobre folhas mortas de C. echinata Lam., exemplar s.n., 15-III-2002, R.A.P. Grandi \& T.V. Silva s.n. (SP307966).

Dictyochaeta simplex (S. Hughes \& W.B. Kendr.) Hol.-Jech., Folia Geobot. Phytotax. 19:434. 1984.

Descrições e ilustrações: Holubová-Jechová (1984), Grandi \& Attili (1996).

Material selecionado: BRASIL. SÃo PAUlo: São Paulo, viveiro da Universidade de São Paulo (USP), próximo ao clube dos professores, sobre folhas mortas de C. echinata Lam., exemplar s.n., 20-XI-2003, R.A.P. Grandi \& T.V. Silva s.n. (SP307979).

Dictyosporium zeylanicum Petch, Ann. Roy. Bot. Gard. Peradeniya 6:252. 1917.

Figuras 1-2

Conidióforos e células conidiogênicas originando-se de hifa somática rente ao substrato, reduzidos, difíceis de serem observados. Conidioma tipo esporodóquio, organizado como uma roseta. Conídios palmados, compostos por (4-)5 fileiras de células, cada fileira geralmente com 6-10 células quadrangulares e fortemente aderidas, ligeiramente constritos nos septos, lisos, castanho-amarelados, as três fileiras do meio um pouco mais escuras que as laterais, organizados em um plano. Conídios elipsóide-alargados ou em forma de U, ápice das fileiras arredondado, fileiras do meio geralmente sobressaindo das demais e com 5-6 células, fileiras laterais recurvadas para o centro do conídio. Base do conídio com uma célula mais ou menos triangular e mais clara que as demais. Total de células por conídio: 33-40. Conídios medindo 32,2-43,7 × 18,0-26,6 $\mu \mathrm{m}$. Largura das células das fileiras: 4,0-6,6 $\mu \mathrm{m}$. Comprimento das fileiras: 27,4-40,0 $\mu \mathrm{m}$.

Material selecionado: BRASIL. SÃo PaUlo: São Paulo, Parque Estadual das Fontes do Ipiranga, Jardim Botânico de São Paulo, sobre folhas mortas de C. echinata Lam., exemplares números 6 e 7 , 6-VI-2002, R.A.P. Grandi \& T.V. Silva s.n. (SP307967).

Distribuição geográfica mundial: Estados Unidos da América, Sri Lanka (Damon 1952). Primeira referência da espécie para o Brasil.

O gênero Dictyosporium foi descrito por Corda em 1836 com a espécie-tipo D. elegans Corda e inclui dois sinônimos: Cattanea e Speira (Damon 1952, Ellis 1971). Chave para identificação de 24 espécies aceitas dentro do gênero foi apresentada por Cai et al. (2003) os quais descreveram D. yunnanensis L. Cai, K.D. Hyde \& McKenzie, espécie próxima a $D$. zeylanicum por apresentar conídios com a mesma forma e cor. No entanto, D. yunnanensis apresenta conídios com 5-7 fileiras de células, 22-38 $\mu$ m de largura e 19-47 células por conídio. O material isolado apresentou-se com medidas um pouco maiores que as de Damon (1952). Dictyosporium zeylanicum tem dois sinônimos: Cheiromyces digitatus Martin e Speira digitata (Martin) Damon (Damon 1952) os quais não foram referidos para o Brasil. Até o momento D. hymenaearum Bat. \& J.L. Bezerra e D. minus (Sacc.) Damon são as espécies já relatadas para o país (Silva \& Minter 1995). 
Epicoccum nigrum Link, Mag. Ges. naturf. Fr. Berl. 7:32. 1815.

Descrições e ilustrações: Ellis (1971), Gusmão \& Grandi (1997).

Material selecionado: BRASIL. São PAULO: São Paulo, Parque Estadual das Fontes do Ipiranga, Jardim Botânico de São Paulo, sobre folhas mortas de C. echinata Lam., exemplar número 102, 13-X-2003, R.A.P. Grandi \& T.V. Silva s.n. (SP307968).

Gyrothrix circinata (Berk. \& M.A. Curt.) S. Hughes, Can. J. Bot. 36:771. 1958.

Descrições e ilustrações: Pirozynski (1962), Grandi \& Gusmão (1995).

Material selecionado: BRASIL. São PAUlo: São Paulo, Parque Estadual das Fontes do Ipiranga, Jardim Botânico de São Paulo, sobre folhas mortas de C. echinata Lam., exemplar número 64, 2-X-2002, R.A.P. Grandi \& T.V. Silva s.n. (SP307956).

Gyrothrix grisea Piroz., Mycol. Pap. 84:17. 1962. Figuras 3-4

Setas eretas, extensas, irregularmente ramificadas, sinuosas, lisas, base com 2-3 septos antes da primeira ramificação, castanho-amareladas e translúcidas, 250-307,3 × 3,4-4,4 $\mu \mathrm{m}$ na base. Setas com ápice afilado, recurvado, castanho-claro, 0,9-1,0 $\mu \mathrm{m}$ largura. Conidióforos inconspícuos. Células conidiogênicas na base das setas, lageniformes ou em forma de moringa, anelídicas, castanho-claras, 6,8-7,7 × 3,2-3,9 $\mu \mathrm{m}$. Conídios unicelulares, fusiformes, estreitos, lisos, hialinos, formando uma massa esbranquiçada na base das setas, $11,8-15,1 \times 1,4-1,8 \mu \mathrm{m}$.

Material selecionado: BRASIL. SÃo PAULO: São Paulo, Parque Estadual das Fontes do Ipiranga, Jardim Botânico de São Paulo, sobre folhas mortas de C. echinata Lam., exemplar número 102, 13-X-2003, R.A.P. Grandi \& T.V. Silva s.n. (SP307969).

Distribuição geográfica mundial: Cuba (MercadoSierra 1984), Índia (Pirozynski 1962). Primeira referência para o Brasil.

A espécie em questão é próxima de G. citricola Piroz. porém nesta as setas são menores e os conídios medem 8,0-14,0 × 1,5-2,0 $\mu$ m, com média de 9,0 × 1,5 $\mu \mathrm{m}$ (Pirozynski 1962). A média aqui obtida para os conídios de G. grisea é de $13,2 \times 1,5 \mu \mathrm{m}$, semelhante à de Pirozynski (1962). Espécies de Gyrothrix são muito comuns em folhedo ocorrendo com freqüência em substratos de plantas tanto em regiões temperadas como nos trópicos. Algumas espécies já foram caracterizadas e ilustradas para o Brasil (Grandi \& Gusmão 1995, Gusmão 2003, Grandi 2004).

Gyrothrix microsperma (Höhn.) Piroz., Mycol. Pap. 84:14. 1962.

Descrições e ilustrações: Pirozynski (1962), Gusmão (2003).

Material selecionado: BRASIL. SÃo PaUlo: São Paulo, Parque Estadual das Fontes do Ipiranga, Jardim Botânico de São Paulo, sobre folhas mortas de C. echinata Lam., exemplares números 68 e 69, 30-I-2002, R.A.P. Grandi \& T.V. Silva s.n. (SP307970).

Gyrothrix podosperma (Corda) Rabenh., Deutchl. Krypt.-fl. 1:72. 1844.

Descrições e ilustrações: Pirozynski (1962), Grandi \& Gusmão (1995).

Material selecionado: BRASIL. SÃo Paulo: São Paulo, Parque Estadual das Fontes do Ipiranga, Jardim Botânico de São Paulo, sobre folhas mortas de C. echinata Lam., exemplar número 22, 7-VIII-2002, R.A.P. Grandi \& T.V. Silva s.n. (SP307980).

Henicospora minor P.M. Kirk \& B. Sutton, Trans. Br. mycol. Soc. 75:249. 1980.

Descrições e ilustrações: Kirk \& Sutton (1980), Grandi \& Silva (2003).

Material selecionado: BRASIL. SÃo PaUlo: São Paulo, Parque Estadual das Fontes do Ipiranga, Jardim Botânico de São Paulo, sobre folhas mortas de C. echinata Lam., exemplar número 22, 7-VIII-2002, R.A.P. Grandi \& T.V. Silva s.n. (SP307872).

Humicola grisea Traaen, Nyt Mag. Naturvid. 52:34. 1914.

Descrições e ilustrações: Ellis (1971), Grandi \& Gusmão (1996).

Material selecionado: BRASIL. SÃo Paulo: São Paulo, Parque do Ibirapuera, sobre folhas mortas de C. echinata Lam., exemplar s.n., 28-XI-2002, R.A.P. Grandi \& T.V. Silva s.n. (SP307971).

Mycoleptodiscus brasiliensis B. Sutton \& Hodges, Nova Hedwigia 27:694. 1976.

Descrições e ilustrações: Sutton \& Hodges Junior (1976), Grandi \& Attili (1996).

Material selecionado: BRASIL. SÃo PAUlo: São Paulo, Instituto de Pesquisas Tecnológicas, USP, sobre folhas mortas de C. echinata Lam., exemplar s.n., 9-VI-2003, R.A.P. Grandi \& T.V. Silva s.n. (SP307972). 
Mycoleptodiscus indicus (V.P. Sahni) B. Sutton, Trans. Brit. mycol. Soc. 60:528. 1973.

Descrições e ilustrações: Sutton (1973), Bezerra \& Ram (1986).

Material selecionado: BRASIL. São Paulo: São Paulo, Parque Estadual das Fontes do Ipiranga, Jardim Botânico de São Paulo, sobre folhas mortas de C. echinata Lam., exemplar s.n., 15-III-2002, R.A.P. Grandi \& T.V. Silva s.n. (SP307957).

Periconia byssoides Pers., Synop. Meth. Fung. p.686, 1801.

Descrições e ilustrações: Batista et al. (1960), Ellis (1971).

Material selecionado: BRASIL. São PAUlo: São Paulo, Parque Estadual das Fontes do Ipiranga, Jardim Botânico de São Paulo, sobre folhas mortas de C. echinata Lam., exemplar s.n., 15-III-2002, R.A.P. Grandi \& T.V. Silva s.n. (SP307958).

Pithomyces cf. graminicola R.Y. Roy \& J.B. Ray, Trans. Br. mycol. Soc. 51:154. 1968.

Figuras 5-7

Conidióforos e células conidiogênicas não observados. Conídios oblongos ou elíptico-alargados, retos ou com ligeira curvatura, 2(-3) septados apenas transversalmente, lisos, célula apical arredondada, célula basal cônico-truncada ou reta, com cicatriz escura, podendo apresentar fragmento da parede da célula conidiogênica revelando liberação rexolítica, ligeiramente constritos na região dos septos, castanho-amarelados, 11,7-20,5 × 4,9-8,2 $\mu \mathrm{m}$.

Material selecionado: BRASIL. São PAULO: São Paulo, Parque Estadual das Fontes do Ipiranga, Jardim Botânico de São Paulo, sobre folhas mortas de C. echinata Lam., exemplar número 102, 13-X-2003, R.A.P. Grandi \& T.V. Silva s.n. (SP307982).

Distribuição geográfica mundial: Austrália, Estados Unidos da América, Índia, Suazilândia, Taiwan (MorganJones 1987), Brasil (Santos et al. 1989), China (Matsushima 1975), Peru (Matsushima 1995).

Descrição taxonômica e ilustração não foram encontradas para o táxon em questão, motivo pelo qual incluem-se aqui. Pithomyces graminicola apresenta a maioria dos conídios com dois septos apenas transversais, raramente longitudinais, o que o diferencia das demais espécies publicadas (Ellis 1971, 1976, Matsushima 1975). No material isolado também foram observados conídios com um ou três septos, embora menos freqüentes, o que concorda com Roy \& Rai (1968). O táxon foi estudado em detalhes por Morgan-
Jones (1987) que estabeleceu dois sinônimos: P. funiculosus M.E. Palm et al. e P. pavgii (V.R. Nath) M.E. Palm et al. A diferenciação entre $P$. graminicola e $P$. sacchari (Speg.) M.B. Ellis é problemática, tendo as duas espécies variabilidade métrica conidial muito grande, mas permanecendo separadas (Morgan-Jones 1987). No Brasil há notícia da espécie apenas como citação (Santos et al. 1989).

Pseudodictyosporium wauense Matsush., Microfungi of the Solomon Islands and Papua - New Guinea p.46. 1971.

Descrições e ilustrações: Matsushima (1971), Grandi \& Silva (2003).

Material selecionado: BRASIL. SÃo PAUlo: São Paulo, Parque Estadual das Fontes do Ipiranga, Jardim Botânico de São Paulo, sobre folhas mortas de C. echinata Lam., exemplares números 19 e 21, 16-IV-2002, R.A.P. Grandi \& T.V. Silva s.n. (SP307873).

Scolecobasidium humicola G.L. Barron \& L.V. Busch, Can. J. Bot. 40:83. 1962.

Descrições e ilustrações: Ellis (1971), Grandi (1991).

Material selecionado: BRASIL. São PAULO: São Paulo, Parque Estadual das Fontes do Ipiranga, Jardim Botânico de São Paulo, sobre folhas mortas de C. echinata Lam., exemplar número 102, 13-X-2003, R.A.P. Grandi \& T.V. Silva s.n. (SP307983).

Scolecobasidium variabile G.L. Barron \& L.V. Busch, Can. J. Bot. 40:83. 1962.

Descrições e ilustrações: Ellis (1971), Grandi (1985).

Material selecionado: BRASIL. São PAULO: São Paulo, Parque Estadual das Fontes do Ipiranga, Jardim Botânico de São Paulo, sobre folhas mortas de C. echinata Lam., exemplar s.n., 5-II-2003, R.A.P. Grandi \& T.V. Silva s.n. (SP307984).

Scytalidium lignicola Pesante, Annali Sper. agr., N.S., 11, Suppl.: CCLXI-CCLXV. 1957.

Descrições e ilustrações: Ellis (1971), Grandi (1991).

Material selecionado: BRASIL. SÃo PAulo: São Paulo, Parque Estadual das Fontes do Ipiranga, Jardim Botânico de São Paulo, sobre folhas mortas de C. echinata Lam., exemplares números 6 e 7, 6-VII-2002, R.A.P. Grandi \& T.V. Silva s.n. (SP307973). 

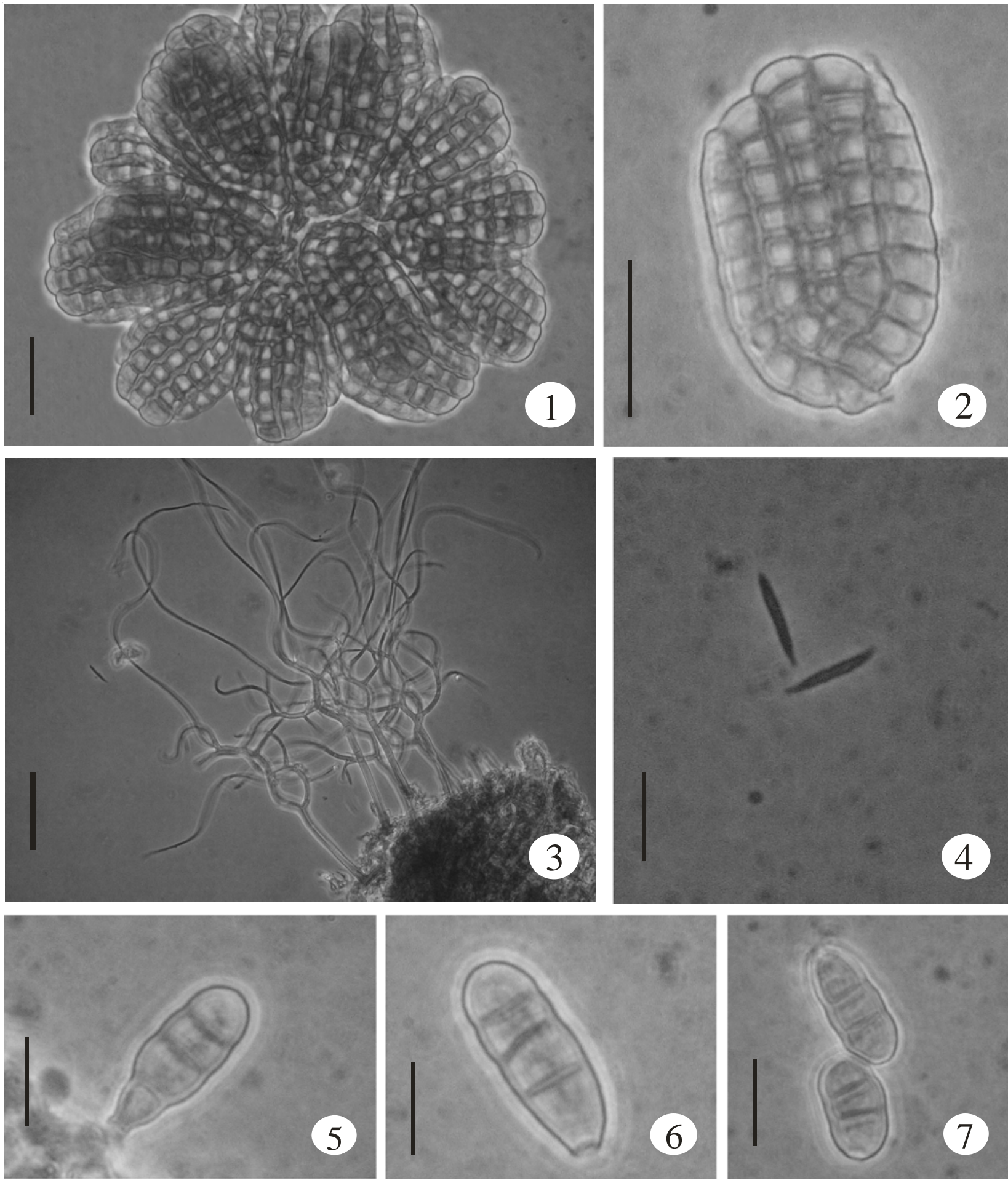

Figuras 1-2. Dictyosporium zeylanicum Petch. 1. Esporodóquio em roseta. 2. Conídio com cinco fileiras de células fortemente aderidas. 3-4. Gyrothrix grisea Piroz. 3. Aspecto geral das setas. 4. Conídios. 5-7. Pithomyces cf. graminicola R.Y. Roy \& J.B. Ray. 5. Conídio com três septos e célula basal cônico-tuncada. 6. Conídio com três septos e célula basal reta. 7. Conídios com dois septos. Barras = $20 \mu \mathrm{m}$ (1-2); $50 \mu \mathrm{m}$ (3); $10 \mu \mathrm{m}$ (4-7).

Figures 1-2. Dictyosporium zeylanicum Petch. 1. Sporodochium like a rosette. 2. Conidium with five rows of cells strongly adhering one to another. 3-4. Gyrothrix grisea Piroz. 3. General aspects of setae. 4. Conidia. 5-7. Pithomyces cf. graminicola R.Y. Roy \& J.B. Ray. 5. Conidium with three septa and basal cell obconical and truncate. 6. Conidium with three septa and straight basal cell. 7. Conidia with two septa. Bars = $20 \mu \mathrm{m}$ (1-2); $50 \mu \mathrm{m}$ (3); $10 \mu \mathrm{m}$ (4-7). 
Speiropsis scopiformis Kuthub. \& Nawawi, Trans. Brit. mycol. Soc. 89:584. 1987.

Descrições e ilustrações: Kuthubutheen \& Nawawi (1987), Gusmão et al. (2001).

Material selecionado: BRASIL. São PAUlo: São Paulo, Parque Estadual das Fontes do Ipiranga, Jardim Botânico de São Paulo, sobre folhas mortas de C. echinata Lam., exemplares números 68 e 69, 30-I-2002, R.A.P. Grandi \& T.V. Silva s.n. (SP307985).

Sporidesmium filiferum Piroz., Mycol. Pap. 129:55. 1972.

Descrições e ilustrações: Watanabe (1996), Grandi \& Silva (2003).

Material selecionado: BRASIL. São PAUlo: São Paulo, Parque Estadual das Fontes do Ipiranga, Jardim Botânico de São Paulo, sobre folhas mortas de C. echinata Lam., exemplares números 68 e 69, 30-I-2002, R.A.P. Grandi \& T.V. Silva s.n. (SP307874).

Sporidesmium cf. filirostratum Cabello, Cazau \& Aramb., Mycotaxon 38:16. 1990.

Figura 8

Conidióforos eretos, septados, lisos, sem ramificações, castanhos. Células conidiogênicas integradas, terminais, cilíndricas, castanhas, com proliferação percorrente (até cinco anelações). Conídios fusiformes, estreitos, com 6-10 pseudoseptos transversais, lisos, castanho-claros, 81,5-105,2 $\times$ 4,3-5,1 $\mu \mathrm{m}$. Ápice rostrado, fino e hialino, com dois septos verdadeiros próximos à célula apical; base cônico-truncada, 2,8-3,0 $\mu \mathrm{m}$ larg.

Material selecionado: BRASIL. SÃo PaUlo: São Paulo, Mata da USP (viveiro) próximo ao clube dos professores, sobre folhas mortas de C. echinata Lam., exemplar s.n., 20-XI-2003, R.A.P. Grandi \& T.V. Silva s.n. (SP307942).

Distribuição geográfica mundial: Argentina (Cabello et al. 1990). Primeira referência para o Brasil.

O gênero Sporidesmium foi proposto por Link em 1809, com a espécie-tipo S. atrum Link (Ellis 1971). O histórico do gênero, as dificuldades de comparação das espécies descritas e o estabelecimento da própria espécie-tipo, até a metade do século $\mathrm{XX}$, foram relatados por Ellis (1958), que propôs o gênero Podoconis, descrito por Boedijn em 1933, como sinônimo. Hernández-Gutiérrez \& Sutton (1997) informaram que mais de 150 espécies foram descritas dentro do gênero e apresentaram as características marcantes que levaram à transferência de várias espécies de
Sporidesmium para seis gêneros afins, incluindo a proposição de mais dois, Imimyces e Linkosia, porém contestados por Shoemaker \& Hambleton (2001). Estes últimos autores fizeram cinco novas combinações para espécies de Sporidesmium incluídas em Imimyces. Portanto, não há, até o momento, concordância entre autores, revisão crítica, nem chave que abarque todos os epítetos dentro do gênero. A única publicação que se tem de S. filirostratum é a de Cabello et al. (1990), que isolaram a espécie de graveto em decomposição flutuando na parte poluída do Rio Santiago, Buenos Aires, Argentina. O material isolado a partir de C. echinata ocorreu em pequena quantidade e em apenas uma amostra; os conidióforos não puderam ser medidos por estarem com a parte basal imersa no substrato e a largura dos conídios apresentou-se um pouco menor que na descrição original (Cabello et al. 1990).

Sporidesmium inflatum (Berk. \& Ravenel) M.B. Ellis, Mycol. Pap. 70:70. 1958.

Figuras 9-10

Conidióforos eretos, sem ramificações, lisos, ápice truncado, castanhos, 65,7-223,2 × 5,3-7,3 $\mu \mathrm{m}$. Células conidiogênicas integradas, terminais, cilíndricas, com proliferação percorrente, castanhas. Conídios sigmóides, (4-)5 septados, lisos, constritos nos septos, castanhos; base cônico-truncada, duas ou três células medianas mais escuras que as demais, célula apical alongada, castanho-clara a hialina, 59,0-86,6 × 12,7-18,8 $\mu \mathrm{m}$. Célula apical 3,9-5,5 $\mu \mathrm{m}$ largura; célula basal 5,3-6,6 $\mu \mathrm{m}$ largura na junção com a célula conidiogênica.

Material selecionado: BRASIL. SÃo PAULO: MojiGuaçu, Fazenda Campininha, bosque do pau-brasil, sobre folhas mortas de C. echinata Lam., exemplar s.n., 13-VI-2003, R.A.P. Grandi \& T.V. Silva s.n. (SP307945).

Distribuição geográfica mundial: Cuba (MercadoSierra 1984), Estados Unidos da América (Ellis 1958), Guiné (Ellis 1971), Japão (Matsushima 1975), PapuaNova Guiné (Matsushima 1971), Peru (Matsushima 1993), Serra Leoa (Ellis 1958), Taiwan (Matsushima 1980) e Uganda (Ellis 1971). Primeira referência para o Brasil.

O material obtido apresentou-se com as medidas um pouco menores que os da descrição original (Ellis 1958) mas dentro da circunscrição da espécie quando comparado com outros espécimes estudados (Matsushima 1971, 1975, Mercado-Sierra 1984).

Sporidesmium triangulare Matsush., Microfungi of the Solomon Islands and Papua - New Guinea p.59. 1971. Figuras 11-13. 
Conidióforos eretos, sem ramificação, septados, vigorosos, ápice truncado, castanhos, 78,9-118,3 × 3,8-4,8 $\mu \mathrm{m}$. Célula conidiogênica integrada, terminal, cilíndrica, com proliferação percorrente, lageniforme, castanha. Conídios com três septos apenas transversais, obclavados ou triangulares; célula basal com ornamentação verrucosa conspícua, mais escura e mais larga que as demais, células intermediárias com pouca ou nenhuma ornamentação, ápice com célula lisa, castanho-clara a hialina, 20,3-27,2 × 12,2-16,0 $\mu \mathrm{m}$. Célula basal do conídio com resquício da célula conidiogênica, demonstrando liberação rexolítica.

Material selecionado: BRASIL. SÃo PAULO: São Paulo, Universidade de Santo Amaro, sobre folhas mortas de C. echinata Lam., exemplar s.n., 2-II-2004, C.G. Moreira s.n. (SP307943).

Distribuição geográfica mundial: Ilhas Salomão (Matsushima 1971). Primeira referência para o Brasil.

A espécie em questão concorda com a descrição feita por Matsushima (1971). Sporidesmium aturbinatum (S. Hughes) M.B. Ellis é semelhante mas a largura dos conídios é menor (Ellis 1976). Penzigomyces cookei (S. Hughes) Subram., cujo sinônimo é S. cookei (S. Hughes) M.B. Ellis também é semelhante porém exibe conídios com 7-10 $\mu \mathrm{m}$ de largura (Ellis 1971, McKenzie 1995).

Tetraploa aristata Berk. \& Broome, Ann. Mag. nat. Hist. series 2, 5:459. 1850. (1992).

Descrições e ilustrações: Ellis (1971), Grandi

Material selecionado: BRASIL. São PaUlo: São Paulo, Parque Estadual das Fontes do Ipiranga, Jardim Botânico de São Paulo, sobre folhas mortas de C. echinata Lam., exemplar número 102, 13-X-2003, R.A.P. Grandi \& T.V. Silva s.n. (SP307981).

Thozetella cristata Piroz. \& Hodges, Can. J. Bot. 51:168. 1973.

Descrições e ilustrações: Pirozynski \& Hodges Junior (1973), Gusmão \& Grandi (1997).

Material selecionado: BRASIL. São PAUlo: São Paulo, Parque Estadual das Fontes do Ipiranga, Jardim Botânico de São Paulo, sobre folhas mortas de C. echinata Lam., exemplares números 68 e 69, 30-I-2002, R.A.P. Grandi \& T.V. Silva s.n. (SP307961).

Thozetella cubensis R.F. Castañeda \& G.R.W. Arnold, Rev. Jard. Bot. Nac. 6:51. 1985.
Descrições e ilustrações: Castañeda-Ruíz \& Arnold (1985), Gusmão \& Grandi (1997).

Material selecionado: BRASIL. SÃo PaUlo: São Paulo, Parque Estadual das Fontes do Ipiranga, Jardim Botânico de São Paulo, sobre folhas mortas de C. echinata Lam., exemplar número 22, 7-VIII-2002, R.A.P. Grandi \& T.V. Silva s.n. (SP307962).

Venustusynnema ciliata (R.F. Castañeda, G.R.W. Arnold \& A.G. Guerra) R.F. Castañeda \& W.B. Kendrick, Univ. Waterloo Biol. Ser. 32:45. 1990.

Descrições e ilustrações: Castañeda-Ruíz \& Kendrick (1990), Grandi \& Gusmão (2002).

Material selecionado: BRASIL. São PAULO: São Paulo, Bairro de Pinheiros, projeto Pomar, sobre folhas mortas de C. echinata Lam., exemplar s.n., 28-XI-2002, R.A.P. Grandi \& T.V. Silva s.n. (SP307986).

Vermiculariopsiella immersa (Desm.) Bender, Mycologia 24:412. 1932.

Descrições e ilustrações: Sutton (1978, como Oramasia hirsuta Urries), Nawawi et al. (1990), Gusmão (2003).

Material selecionado: BRASIL. SÃo PaUlo: São Paulo, Faculdade de Saúde Pública (USP), Av. Dr. Arnaldo, sobre folhas mortas de C. echinata Lam., exemplar s.n., 12-VIII-2003, R.A.P. Grandi \& T.V. Silva s.n. (SP307977).

Veronaea botryosa Cif. \& Montemart., Atti Ist. bot. Univ. Lab. crittogam. Pavia, Ser. 5, 15:68. 1957.

Figuras 14-16

Conidióforos eretos ou sinuosos, solitários ou em pequenos grupos, septados, não-ramificados, lisos, castanhos, 35,2-84,4 × 3,0-3,8 $\mu \mathrm{m}$. Células conidiogênicas apicais, integradas, simpodiais, com dentículos minúsculos, mais claras que o conidióforo. Conídios elipsóides, 1(-2) septados, lisos, castanho-claros, com apículo na célula basal às vezes pouco perceptível, 5,7-11,9 × 2,5-3,2 $\mu \mathrm{m}$.

Material selecionado: BRASIL. São PaUlo: São Paulo, Bairro de Pinheiros, projeto Pomar, sobre folhas mortas de C. echinata Lam., exemplar s.n., 28-XI-2002, R.A.P. Grandi \& T.V. Silva s.n. (SP307974).

Distribuição geográfica mundial: Brasil, China (Montenegro et al. 1996), Cuba (Mercado Sierra \& Castañeda-Ruíz 1987), Equador, Peru (Matsushima 1993), Ilhas Salomão (Matsushima 1971), Índia (Rao \& Hoog 1986), Itália (Ellis 1971) e Reino Unido (Kirk \& Spooner 1984). 

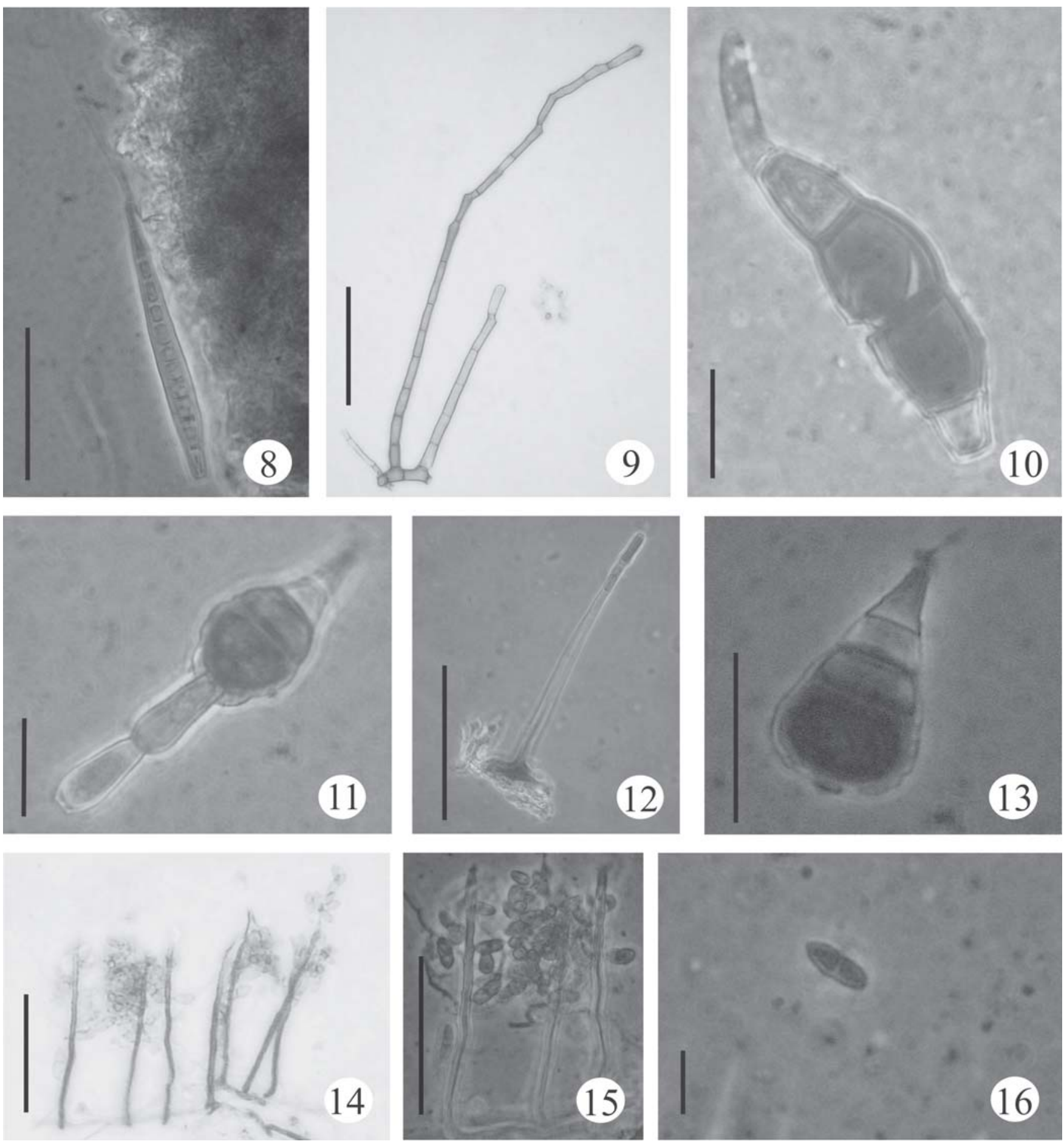

Figura 8. Conídio de Sporidesmium cf. filirostratum Cabello. 9-10. Sporidesmium inflatum (Berk. \& Ravenel) M.B. Ellis. 9. Aspecto geral de dois conidióforos. 10. Conídio. 11-13. Sporidesmium triangulare Matsush. 11. Células conidiogênicas com proliferação percorrente e conídio. 12. Conidióforo. 13. Conídio com célula basal ornamentada. 14-16. Veronaea botryosa Cif. \& Montemart. 14. Aspecto geral. 15. Detalhe dos conidióforos e conídios. 16. Conídio. Barras = $50 \mu \mathrm{m}$ (8-9, 12, 14-15); $20 \mu \mathrm{m}$ $(10-11,13) ; 10 \mu \mathrm{m}(16)$.

Figure 8. Conidium of Sporidesmium cf. filirostratum Cabello. 9-10. Sporidesmium inflatum (Berk. \& Ravenel) M.B. Ellis. 9. Two conidiophores. 10. Conidium. 11-13. Sporidesmium triangulare Matsush. 11. Percurrent conidiogenous cells and conidium. 12. Conidiophore. 13. Conidium with ornamented basal cell. 14-16. Veronaea botryosa Cif. \& Montemart. 14. General aspects. 15. Conidiophores and conidia. 16. Conidia. Bars = $50 \mu \mathrm{m}$ (8-9, 12, 14-15); $20 \mu \mathrm{m}(10-11,13) ; 10 \mu \mathrm{m}(16)$. 
Descrição taxonômica e ilustração não foram encontradas para o táxon em questão, motivo pelo qual incluem-se aqui. Matsushima (1993) informa que V. botryosa tem dois sinônimos: Sympodina coprophila Subram. \& Lodha e Scolecobasidium coprophilum (Subram. \& Lodha) Matsush., também não encontrados na literatura brasileira. Montenegro et al. (1996), em trabalho sobre isolamento de fungos patogênicos de solo da região de Botucatu, Estado de São Paulo, isolaram a espécie e informaram ser aquele o primeiro relato para a América do Sul, sem fornecer dados morfológicos. O material foi obtido em apenas uma amostra e os conidióforos apresentaram-se menores que em outros isolamentos (Ellis 1971, Mercado Sierra \& CastañedaRuíz 1987, Matsushima 1987, 1993).

Volutella ciliata (Alb. \& Schwein.) Fr., Syst. Mycol. 3:466. 1832.

Descrições e ilustrações: Matsushima (1971), Pfenning (1993).

Material selecionado: BRASIL. SÃo PAULO: São Paulo, Parque Estadual das Fontes do Ipiranga, Jardim Botânico de São Paulo, sobre folhas mortas de C. echinata Lam., exemplar número 102, 13-X-2003, R.A.P. Grandi \& T.V. Silva s.n. (SP307978).

Wiesneriomyces laurinus (Tassi) P.M. Kirk, Trans. Brit. mycol. Soc. 82:748. 1984.

Descrições e ilustrações: Ellis (1971, como Wiesneriomyces javanicus Koorders), Gusmão \& Grandi (1997).

Material selecionado: BRASIL. São PaUlo: São Paulo, Parque Estadual das Fontes do Ipiranga, Jardim Botânico de São Paulo, sobre folhas mortas de C. echinata Lam., exemplar número 102, 13-X-2003, R.A.P. Grandi \& T.V. Silva s.n. (SP307963).

Zygosporium masonii S. Hughes, Mycol. Pap. 44:15. 1951.

Descrições e ilustrações: Batista \& Lima (1960), Wang \& Baker (1967).

Material selecionado: BRASIL. SÃo PAULO: São Paulo, Parque Estadual das Fontes do Ipiranga, Jardim Botânico de São Paulo, sobre folhas mortas de C. echinata Lam., exemplares números 62 e 64, 2-X-2002, R.A.P. Grandi \& T.V. Silva s.n. (SP307976).

\section{COELOMYCETES}

Chaetospermum sp.

Descrições e ilustrações: Sutton (1980).
Material selecionado: BRASIL. SÃo PaUlo: São Paulo, Parque Estadual das Fontes do Ipiranga, Jardim Botânico de São Paulo, sobre folhas mortas de C. echinata Lam., exemplar s.n., 15-III-2002, R.A.P. Grandi \& T.V. Silva s.n. (SP307987).

Chaetospermum foi estabelecido por Saccardo em 1892. Tem quatro gêneros como sinônimos, todos descritos até 1930 (Sutton 1980). Os materiais isolados sobre $C$. echinata, apesar de terem ocorrido em quatro amostras, não concordaram com as três espécies apresentadas por Sutton (1980) porém enquadraramse somente nesse gênero pela morfologia dos conídios, os quais medem 28,4-33,5 × 9,7-11,8 $\mu \mathrm{m}$. A consulta a Kirk \& Cooper (2005) revelou nove espécies publicadas, algumas já apontadas como sinônimas de uma das três descritas por Sutton (1980); este autor considera que o conidioma é muito variável, sendo as três espécies mantidas dentro do gênero até que o mesmo seja revisto. Decidiu-se incluir o táxon neste trabalho para não perder o registro de sua ocorrência sobre o folhedo de C. echinata.

Pestalotiopsis guepinii (Desm.) Steyaert, Bull. Jard. bot. Brux.19:312. 1949.

Descrições e ilustrações: Sutton (1980), Grandi (2004).

Material selecionado: BRASIL. São PAULO: São Paulo, Parque Estadual das Fontes do Ipiranga, Jardim Botânico de São Paulo, sobre folhas mortas de C. echinata Lam., exemplar s.n., 15-III-2002, R.A.P. Grandi \& T.V. Silva s.n. (SP307959).

Satchmopsis brasiliensis B. Sutton \& Hodges, Nova Hedwigia 26:3. 1975.

Descrições e ilustrações: Sutton (1975, 1980).

Material selecionado: BRASIL. São PAULO: São Paulo, Parque Estadual das Fontes do Ipiranga, Jardim Botânico de São Paulo, sobre folhas mortas de C. echinata Lam., exemplares números 19 e 21, 16-IV-2002, R.A.P. Grandi \& T.V. Silva s.n. (SP307960).

A análise de diversos tipos de folhedo utilizando a técnica da lavagem sucessiva e incubação em câmarasúmidas tem revelado número expressivo de táxons associados à decomposição. Assim, dentre as espécies de plantas estudadas até o momento, Miconia cabussu Hoehne proveniente da Reserva Biológica de Paranapiacaba (RBP) destacou-se, revelando 53 Hyphomycetes decompositores (Gusmão et al. 2001). Com Caesalpinia echinata Lam., material do presente trabalho, obteve-se 46 táxons e com Cedrela fissilis 
Vell. proveniente do Horto Florestal de Maringá (PR), 40 (Grandi \& Gusmão 1995, Gusmão \& Grandi 1996, 1997). O folhedo de outras plantas foi objeto desse tipo de estudo porém revelou número menor de espécies de anamorfos: Euterpe edulis Mart., coletado na RBP com 26 (Grandi 1999), Tibouchina pulchra Cogn., coletado na RBP com 22 (Grandi \& Gusmão 2002), Alchornea triplinervia (Spreng.) Müll. Arg. coletado na RBP e C. fissilis coletado na Reserva Florestal da Cidade Universitária (USP, São Paulo), ambos com 19 (Grandi et al. 1995, Grandi 1998) e A. triplinervia coletado na Reserva Ecológica de Juréia-Itatins com 16 (Grandi \& Attili 1996).

Mesmo com os ecossistemas e periodicidade de coleta não sendo comparáveis, a técnica da lavagem sucessiva tem sido utilizada com sucesso, como explanado em Grandi \& Gusmão (2002) e, de acordo com o número de táxons obtidos, o folhedo de C. echinata foi um dos que mais contribuiu para o aumento do conhecimento de anamorfos no Brasil.

Agradecimentos - À Fapesp pelo apoio financeiro ao projeto (processo 2000/06422-4) e às pesquisadoras Diclá Pupo Santos e Mutue Toyota Fujii, bem como às estagiárias do Laboratório de Algas Marinhas do Instituto de Botânica, pelo auxílio na confecção das fotomicrografias.

\section{Referências bibliográficas}

BATISTA, A.C. \& LIMA, J.A. 1960. Um grupo de fungos da atmosfera de Recife. Publicações do Instituto de Micologia da Universidade do Recife 297:1-24.

BATISTA, A.C., BEZERRA, J.L. \& MAIA, H.S. 1960. Vonarxia gen. n. e outros imperfecti fungi. Publicações do Instituto de Micologia da Universidade do Recife 283:1-32.

BATISTA, A.C., MAIA, H.S. \& BEZERRA, J.L. 1965. Brachysporium minutum n. sp. e outros Dematiaceae fragmospóricos. Publicações do Instituto de Micologia da Universidade do Recife 446:1-19.

BEZERRA, J.L. \& RAM, A. 1986. A crosta-negra da baunilha (Vanilla fragrans) causada por Mycoleptodiscus indicus (Moniliales, Hyphomycetes). Fitopatologia Brasileira 2:717-724.

CABELLO, M., CAZAU, C. \& ARAMBARRI, A. 1990. New Hyphomycetes from Santiago River. III. (Buenos Aires Province, Argentina). Mycotaxon 38:15-19.

CAI, L., ZHANG, K., MCKENZIE, E.H.C., LUMYONG, S. \& HYDE, K.D. 2003. New species of Canalisporium and Dictyosporium from China and a note on the differences between these genera. Cryptogamie, Mycologie 24:3-11.
CASTAÑEDA-RUIZ, R.F. 1985. Deuteromycotina de Cuba. Hyphomycetes III. Instituto de Investigaciones Fundamentales en Agricultura Tropical “Alejandro de Humboldt”, La Habana.

CASTAÑEDA-RUIZ, R.F. \& ARNOLD, G.R.W. 1985. Deuteromycotina de Cuba. I. Hyphomycetes. Revista del Jardín Botánico Nacional 6:47-67.

CASTAÑEDA-RUIZ, R.F. \& KENDRICK, B. 1990. Conidial fungi from Cuba: I. University of Waterloo Biology Series 32:1-53.

CASTAÑEDA-RUIZ, R.F., GUARRO, J., VELÁZQUEZ-NOA, S. \& GENÉ, J. 2003. A new species of Minimelanolocus and some hyphomycetes records from rain forests in Brazil. Mycotaxon 85:231-239.

DAMON, S.C. 1952. Type studies in Dictyosporium, Speira, and Cattanea. Lloydia 15:110-124.

ELLIS, M.B. 1958. Clasterosporium and some allied Dematiaceae-Phragmosporae. I. Mycological Papers 70:1-89.

ELLIS, M.B. 1971. Dematiaceous Hyphomycetes. Commonwealth Mycological Institute, Kew.

ELLIS, M.B. 1976. More Dematiaceous Hyphomycetes. Commonwealth Mycological Institute, Kew.

GRANDI, R.A.P. 1985. Hyphomycetes do Estado de São Paulo. 1. Espécies do cerrado da Reserva Biológica de Moji-Guaçu. Rickia 12:125-145.

GRANDI, R.A.P. 1991. Hyphomycetes decompositores 2. Táxons associados às raízes de Maranta bicolor Ker. Revista Brasileira de Biologia 51:133-141.

GRANDI, R.A.P. 1992. Hyphomycetes decompositores 3. Espécies associadas às raízes de Stromanthe sanguinea Sond. Revista Brasileira Biologia 52:275-282.

GRANDI, R.A.P. 1998. Hyphomycetes decompositores do folhedo de Alchornea triplinervia (Spreng.) Müll. Arg. Hoehnea 25:133-148.

GRANDI, R.A.P. 1999. Hifomicetos decompositores do folhedo de Euterpe edulis Mart. Hoehnea 26:87-101.

GRANDI, R.A.P. 2004. Anamorfos da serapilheira nos Vales dos Rios Moji e Pilões, município de Cubatão, São Paulo, Brasil. Hoehnea 31:225-238.

GRANDI, R.A.P. \& ATILLI, D.S. 1996. Hyphomycetes on Alchornea triplinervia (Spreng.) Müell. Arg. leaf litter from the Ecological Reserve Juréia-Itatins, State of São Paulo, Brazil. Mycotaxon 60:373-386.

GRANDI, R.A.P. \& GUSMÃO, L.F.P. 1995. Espécies de Gyrothrix (Hyphomycetes) no folhedo de Cedrella fissilis Vell., em Maringá, PR, Brasil. Hoehnea 22:191-196.

GRANDI, R.A.P. \& GUSMÃO, L.F.P. 1996. Hyphomycetes decompositores de raízes de Calathea zebrina (Sims) Lindl. (Marantaceae), provenientes da Reserva Biológica do Alto da Serra de Paranapiacaba, Santo André, SP, Brasil. Revista Brasileira de Botânica 19:165-172. 
GRANDI, R.A.P. \& GUSMÃO, L.F.P. 1998. A técnica da lavagem sucessiva de substratos de plantas como subsídio para estudo da associação fungo/substrato e diversidade de Hyphomycetes nos ecossistemas. In Anais do IV Simpósio Brasileiro de Ecossistemas Brasileiros (S. Watanabe, coord.). Aciesp, São Paulo, v.3, p.80-90.

GRANDI, R.A.P. \& GUSMÃO, L.F.P. 2002. Hyphomycetes decompositores do folhedo de Tibouchina pulchra Cogn. Revista Brasileira de Botânica 25:79-87.

GRANDI, R.A.P. \& SILVA, T.V. 2003. Hyphomycetes sobre folhas em decomposição de Caesalpinia echinata Lam.: ocorrências novas para o Brasil. Revista Brasileira de Botânica 26:489-493.

GRANDI, R.A.P., GRANDI, A.C. \& DELITTI, W.B.C. 1995. Hyphomycetes sobre folhas em decomposição de Cedrella fissilis Vell. Hoehnea 22:27-37.

GUSMÃO, L.F.P. 2003. Microfungos associados a folhas em decomposição de plantas nativas de Campos Rupestres do estado da Bahia, Brasil. Tese de doutorado, Universidade de São Paulo, São Paulo.

GUSMÃO, L.F.P. \& GRANDI, R.A.P. 1996. Espécies do grupo Beltrania (Hyphomycetes) associadas a folhas de Cedrella fissilis Vell. (Meliaceae), em Maringá, PR, Brasil. Hoehnea 23:91-102.

GUSMÃO, L.F.P. \& GRANDI, R.A.P. 1997. Hyphomycetes com conidioma dos tipos esporodóquio e sinema associados a folhas de Cedrella fissilis (Meliaceae), em Maringá, PR, Brasil. Acta Botanica Brasilica 11:123-134.

GUSMÃO, L.F.P., GRANDI, R.A.P. \& MILANEZ, A.I. 2001. Hyphomycetes from leaf litter of Miconia cabussu in the Brazilian atlantic rain forest. Mycotaxon 79:201-213.

HERNÁNDEZ-GUTIÉRREZ, A. \& SUTTON, B.C. 1997. Imimyces and Linkosia, two new genera segregated from Sporidesmium sensu lato, and redescription of Polydesmus. Mycological Research 101:201-209.

HOLUBOVÁ-JECHOVÁ, V. 1984. Lignicolous Hyphomycetes from Czechoslovakia 7. Chalara, Exochalara, Fusichalara and Dictyochaeta. Folia Geobotanica et Phytotaxonomica 19:387-438.

HUGHES, S.J. \& PIROZYNSKI, K.A. 1971. New Zealand fungi 15. Beltraniella, Circinotrichum and Gyrothrix (Syn. Peglionia). New Zealand Journal of Botany 9:39-45.

KIRK, P.M. \& COOPER, J. 2005. Index Fungorum - Authors of Fungal Names. http://www.indexfungorum.org/ Names/Names.asp (acesso em 13/06/2005).

KIRK, P.M. \& SPOONER, B.M. 1984. An account of the fungi of Arran, Gigha and Kintyre. Kew Bulletin 38:503-597.

KIRK, P.M. \& SUTTON, B.C. 1980. Henicospora gen. nov. (Hyphomycetes). Transactions of the British Mycological Society 75:249-253.

KUTHUBUTHEEN, A.J. \& NAWAWI, A. 1987. A new species of Speiropsis from Malaysia. Transactions of the British Mycological Society 89:584-587.
MATSUSHIMA, T. 1971. Microfungi of the Solomon Islands and Papua-New Guinea. Published by the author, Kobe.

MATSUSHIMA, T. 1975. Icones Microfungorum a Matsushima Lectorum. Published by the author, Kobe.

MATSUSHIMA, T. 1980. Saprophytic microfungi from Taiwan. Part 1 Hyphomycetes. Matsushima Mycological Memoirs n.ํㅜ 1. Matsushima Fungus Collection, Kobe.

MATSUSHIMA, T. 1987. Matsushima Mycological Memoirs n. ${ }^{-}$5. Matsushima Fungus Collection, Kobe.

MATSUSHIMA, T. 1993. Matsushima Mycological Memoirs n. ${ }^{-}$7. Matsushima Fungus Collection, Kobe.

MATSUSHIMA, T. 1995. Matsushima Mycological Memoirs n. $\stackrel{-}{ }$ 8. Matsushima Fungus Collection, Kobe.

MCKENZIE, E.H.C. 1995. Dematiaceous Hyphomycetes on Pandanaceae. 5. Sporidesmium sensu lato. Mycotaxon 56:9-29.

MERCADO-SIERRA, A. 1984. Hifomicetes demaciáceos de Sierra del Rosario, Cuba. Academia de Ciencias de Cuba, La Habana.

MERCADO-SIERRA, A. \& CASTAÑEDA-RUIZ, R.F. 1987. Nuevos o raros hifomicetes de Cuba. I. Especies de Cacumisporium, Guedea, Rhinocladium y Veronaea. Acta Botanica Cubana 50:1-7.

MONTENEGRO, M.R., MIYAJI, M., FRANCO, M., NISHIMURA, K., COELHO, K.I., HORIE, Y., MENDES, R.P., SANO, A., FUKUSHIMA, K. \& FECCHIO, D. 1996. Isolation of fungi from nature in the region of Botucatu, State of São Paulo, Brazil, an endemic area of paracoccidioidomycosis. Memórias do Instituto Oswaldo Cruz 91:665-670.

MORGAN-JONES, G. 1987. Notes on Hyphomycetes. LIV. Concerning Pithomyces clavisporus, a new species, P. graminicola and P. pavgii. Mycotaxon 30:29-37.

MORGAN-JONES, G. \& INGRAM, E.G. 1976. Notes on Hyphomycetes. XII. A new species of Chalara. Mycotaxon 4:489-492.

NAWAWI,A., KUTHUBUTHEEN, A.J. \& SUTTON, B.C. 1990. New species and combinations in Vermiculariopsiella (Hyphomycetes). Mycotaxon 37:173-182.

PFENNING, L. 1993. Mikroskopische Bodenpilze des ostamazonischen Regenwaldes (Brasilien). Dissertation zur Erlangung des grades eines Doktors der Naturwissenschaften, Universität Tübingen, Tübingen.

PIROZYNKI, K.A. 1962. Circinotrichum and Gyrothrix. Mycological Papers 84:1-28.

PIROZYNKI, K.A. 1963. Beltrania and related genera. Mycological Papers 90:1-39.

PIROZYNSKI, K.A. \& HODGES JUNIOR, C.S. 1973. New Hyphomycetes from South Carolina. Canadian Journal of Botany 51:157-173.

RAO, V. \& HOOG, G.S. 1986. New or critical Hyphomycetes from India. Studies in Mycology 28:1-84. 
ROY, R.Y. \& RAI, B. 1968. New especies of Lacellina and Pithomyces. Transactions of the British Mycological Society 51:152-155.

SANTOS, A.C., CAVALCANTI, M.A. \& FERNANDES, M.J.S. 1989. Fungos isolados da rizosfera de cana-de-açúcar da Zona da Mata de Pernambuco. Revista Brasileira de Botânica 12:23-29.

SHOEMAKER, R.A. \& HAMBLETON, S. 2001. "Helminthosporium" asterinum, Polydesmus elegans, Imimyces, and allies. Canadian Journal of Botany 79:592-599.

SILVA, M. \& MINTER, D.W. 1995. Fungi from Brazil. Mycological Papers 169:1-585.

SUTTON, B.C. 1973. Pucciniopsis, Mycoleptodiscus and Amerodiscosiella. Transactions of the British Mycological Society 60:525-536.
SUTTON, B.C. 1975. Eucalyptus microfungi: Satchmopsis gen. nov., and new species of Coniella, Coniothyrium and Harknessia. Nova Hedwigia 26:1-16.

SUTTON, B.C. 1978. New and interesting Hyphomycetes from Tampa, Florida. Mycologia 70:784-801.

SUTTON, B.C. 1980. The Coelomycetes. Commonwealth Mycological Institute, Kew.

SUTTON, B.C. \& HODGES JUNIOR, C.S. 1976. Eucalyptus microfungi: Mycoleptodiscus species and Pseudotracylla gen. nov. Nova Hedwigia 27:693-700.

WANG, C.J.K. \& BAKER, G.E. 1967. Zygosporium masonii and Z. echinosporum from Hawaii. Canadian Journal of Botany 45:1945-1952.

WATANABE, T. 1996. Sporidesmium filiferum from Tsukuba, Japan. Mycoscience 37:367-369. 